\title{
Numerical Analysis of Segmental Post Tensioned Concrete Beams Exposed to High Fire Temperature
}

\author{
H. M. Hekmet \\ Department of Civil Engineering, \\ Al-Farabi University College, \\ Baghdad, Iraq \\ maithem_haider@yahoo.com
}

\author{
A. F. Izzet \\ Department of Civil Engineering, \\ University of Baghdad, \\ Baghdad, Iraq \\ amer.f@coeng.uobaghdad.edu.iq
}

\begin{abstract}
The main objective of this study is to characterize the main factors which may affect the behavior of segmental prestressed concrete beams comprised of multi segments. The 3D finite element program ABAQUS was utilized. The experimental work was conducted on twelve simply supported segmental prestressed concrete beams divided into three groups depending on the precast segments number. They all had an identical total length of $3150 \mathrm{~mm}$, but each had different segment numbers ( 9,7 , and 5 segments), in other words, different segment lengths. To simulate the genuine fire disasters, nine beams were exposed to high-temperature flame for one hour, the selected temperatures were $300^{\circ} \mathrm{C}\left(572^{\circ} \mathrm{F}\right), 5^{\circ} 0^{\circ} \mathrm{C}\left(932^{\circ} \mathrm{F}\right)$ and $700^{\circ} \mathrm{C}$ $\left(1292^{\circ} \mathrm{F}\right)$ as recommended by ASTM-E119. Four numerical models have been utilized to represent the unburned and the burned specimens at the three elevated temperatures. Calibration and simulation of the experimental work were conducted, while comparisons were made with the experimental results. These included the prestress effect, load-deflection relation under applied load, and load at failure of the reference beam and the beams after the exposure to fire.
\end{abstract}

Keywords-burning temperature; fire flame; gradual cooling; segmental beam; numerical analysis

\section{INTRODUCTION}

Segmental box girder bridges are one of the major new developments in bridge engineering. This method of construction has many advantages such as substantial economical savings due to the possibility of weatherindependent segment production and a shorter construction period, simple element assembly at job site, replace ability of tendons, independency of concreting and prestressing operations, small light segments, easier checking on profiling of the main external steel, and reduced friction [1]. The strength of reinforced concrete (RC) and prestressed concrete decreases after exposure to fire. The basic fire safety objectives are to protect life and to prevent failure. After a fire, if no collapse happens, there is a possibility of fire-induced damage. Authors in [2, 3] presented the results of nonlinear finite element analysis on segmental concrete beams with external tendons, while authors in [4] investigated the structural behavior of dry joined Externally Prestressed Segmental (EPS) beams under combined stress, i.e. bending, shear and torsion stresses. It was found that the presence of torsion in beams reduces vertical load and vertical deflection at the onset of nonlinearity. Authors in [5] studied the mechanical properties of high-performance concrete (HPC) and the normal-strength concrete (NSC) after exposure to high temperature of $800^{\circ} \mathrm{C}$. Authors in [6] compared strength and durability performance of normal and high-strength pozzolanic concretes including silica fume, fly ash, and blast furnace slag at high temperatures up to $800^{\circ} \mathrm{C}$. Authors in [7] reported that concrete can suffer large damage when exposed to fire, although concrete has low heat conductivity. Concrete materials have significant variations, therefore the structural fire safety capacity of concrete is very complex [8]. Exposed to fire NSC and highstrength concrete (HSC) require constitutive relationships in order to obtain active modeling and to meet particular fire performance standards for fire-resistant prestressed concrete behavior. Authors in [9] studied the mechanical properties of prestressing wires through and after the exposure to fire. The results were compared with the literature and design codes, and empirical formulas were suggested. Authors in [10] studied the effect of prolonged fire (24-hour duration) on reinforced concrete beams made with recycled aggregates. Recycled demolished concrete was used as coarse aggregates in equal proportion with natural coarse aggregates. Normal and rich mix concrete with water-cement ratio equal to 0.54 were used.

Over the past two decades there has been a widespread use of finite element programs to determine the structural performance in standard and natural fire conditions. ABAQUS is a very complex finite element analysis program with many material characteristics and parameters and high accuracy in calculations. The use of modeling in the application of fire modeling has been quickly increasing. There is a constant competition to develop methods and products which will accurately and efficiently solve engineering problems. The model in [11] was considered as "very simple", and used the data already developed from standard fire curves to predict the temperature profile within concrete. Authors in [12] used a method called the "Residual Area Method" to determine the temperature profile for concrete-encased I-sections. From this method, a series of formulas were given to calculate the critical temperature along the steel profile. Authors in [13] studied the structural behavior of unbonded post-tensioned one-way spanning concrete slabs in fire conditions. A nonlinear finite element model has been developed and presented to analyze 
unbonded post-tensioned concrete slabs at high temperatures. The interface between the tendon and the surrounding concrete was modeled, permitting the tendon to retain its profile shape during slab deformation. Temperature distribution throughout the slab, time-longitudinal expansion, time-deflection behavior, time-stress behavior of the tendon and mode of failure were studied and verification with experimental results has been conducted. This research seeks to give an explanation and a simplified estimation of the fire-induced damage produced in precast segmental prestressed concrete beams with the use of 3-D finite element analysis by utilizing the ABAQUS program to calibrate and simulate the experimental work conducted to study the behavior of internally prestressed precast concrete segmental beams with selective parameters such as segment length, number of joints between segments and the exposure to different burning temperatures.

\section{SPC BEAMS SET UP}

The experimental part consisted of 12 simply supported segmental prestressed concrete beams divided into three groups depending on the precast segments number. All the SPC beams were selected and designed with 3150,400 and 400mm length, depth and width, respectively. The first group consisted of SPC beams with 9 segments (350mm segment length), the second group with 7 segments (450mm segment length), and the last group had 5 segments $(630 \mathrm{~mm}$ segment length). Figure 1 shows the schematic shape of the SPC beams for each group.

(a)



(b)

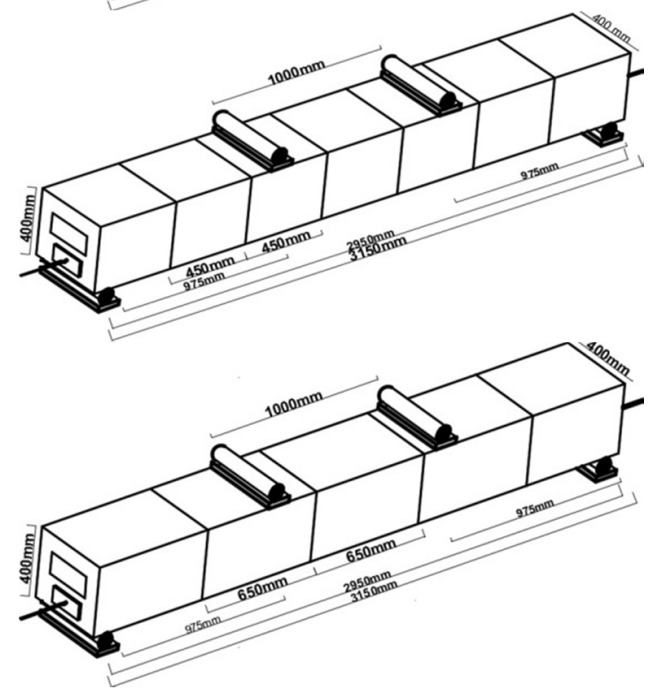

Fig. 1. Schematic and dimensions of the tested SPC beams (a) Group I, (b) Group II, (c) Group III
Figure 2 demonstrates the details of the two opposite contact surfaces of reinforced concrete precast segments, which have been used to assemble the SPC beams, the first consisted projections as shear connecters (keys), in contrast the other consisted pits to engage with the projections. The reinforcement details for the three groups are illustrated in Figure 3. Deformed $8 \mathrm{~mm}$ diameter bars of 486 and $640 \mathrm{MPa}$ yield stress and ultimate strength were used for the longitudinal and ties reinforcement.

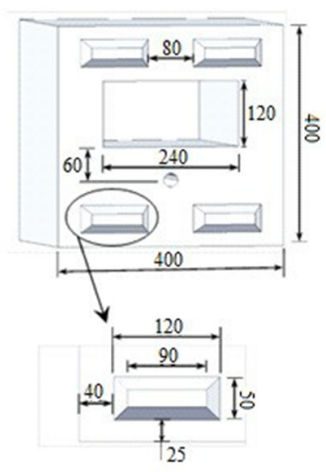

(a) Front view surface

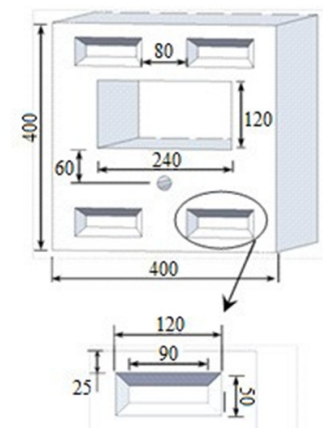

(b) Back view surface
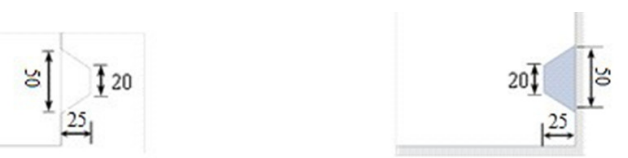

(c) Side view of the shear keys
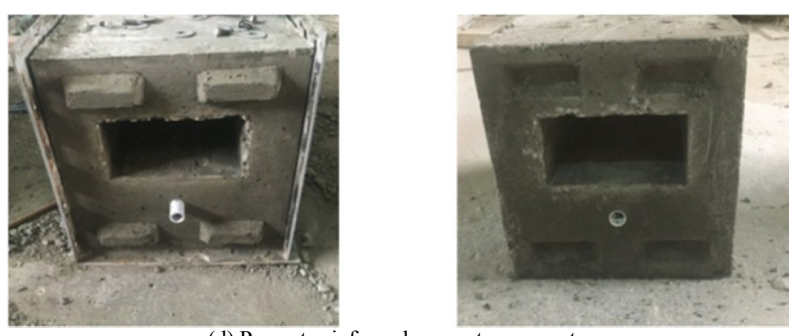

(d) Precast reinforced concrete segments

Fig. 2. Configuration of SPC beam segments (all dimensions in $\mathrm{mm}$ )

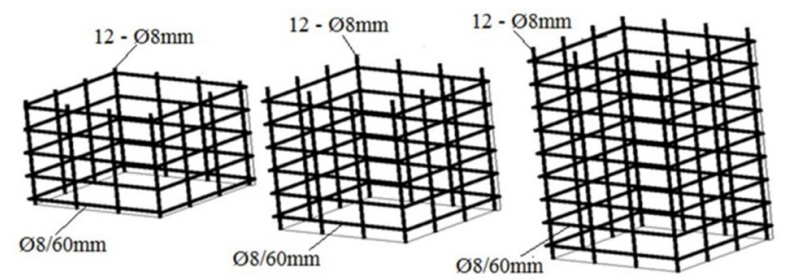

Fig. 3. Reinforcement details of segments for each group of the tested SPC beams

\section{INPUT PARAMETERS IN ABAQUS}

The behavior of a segmental prestressed concrete beam is assumed to be linear elastic during the 3-D analysis. The variables of this study are listed in Table I and the properties of concrete, steel reinforcement and prestressing steel before and after burning are listed in Tables II-IV respectively. 
TABLE I. SEGMENTAL PRESTRESSED CONCRETE BEAMS

\begin{tabular}{|c|c|c|c|c|}
\hline Group & Specimen & $\begin{array}{c}\text { Number of } \\
\text { segments }\end{array}$ & $\begin{array}{c}\text { Segment } \\
\text { length (mm) }\end{array}$ & $\begin{array}{c}\text { Burning } \\
\text { temperature }\left({ }^{\circ} \mathbf{C}\right)\end{array}$ \\
\hline \multirow{4}{*}{ Group I } & SPC-9-R & 9 & 350 & unburned \\
\cline { 2 - 5 } & SPC-9-300 & 9 & 350 & 300 \\
\cline { 2 - 5 } & SPC-9-500 & 9 & 350 & 500 \\
\cline { 2 - 5 } & SPC-9-700 & 9 & 350 & 700 \\
\hline \multirow{5}{*}{ Group II } & SPC-7-R & 7 & 450 & unburned \\
\cline { 2 - 5 } & SPC-7-300 & 7 & 450 & 300 \\
\cline { 2 - 5 } & SPC-7-500 & 7 & 450 & 500 \\
\cline { 2 - 5 } & SPC-7-700 & 7 & 450 & 700 \\
\hline \multirow{4}{*}{ Group III } & SPC-5-R & 5 & 630 & unburned \\
\cline { 2 - 5 } & SPC-5-300 & 5 & 630 & 300 \\
\cline { 2 - 5 } & SPC-5-500 & 5 & 630 & 500 \\
\cline { 2 - 5 } & SPC-5-700 & 5 & 630 & 700 \\
\hline
\end{tabular}

TABLE II. NORMAL STRENGTH CONCRETE MECHANICAL PROPERTIES AT ELEVATED TEMPERATURES [8]

\begin{tabular}{|c|c|c|}
\hline $\begin{array}{c}\text { Temperature } \\
\left({ }^{\circ} \mathbf{C}\right)\end{array}$ & $\begin{array}{c}\text { Compressive } \\
\text { strength } \\
\boldsymbol{f}^{\prime} \mathbf{c}(\mathbf{M P a})\end{array}$ & $\begin{array}{c}\text { Modulus of } \\
\text { elasticity } \\
\text { Ec }(\mathbf{M P a})\end{array}$ \\
\hline Ambient & 33.6 & 27243 \\
\hline 300 & 32.1 & 23810 \\
\hline 500 & 24.4 & 18525 \\
\hline 700 & 13.9 & 11278 \\
\hline
\end{tabular}

TABLE III. STEEL BAR PROPERTIES AFTER BURNING [13]

\begin{tabular}{|c|c|c|}
\hline $\begin{array}{c}\text { Temperature } \\
\left({ }^{\circ} \mathbf{C}\right)\end{array}$ & $\begin{array}{c}\text { Yield Tensile Stress } \\
(\mathbf{M P a})\end{array}$ & $\begin{array}{c}\text { Ultimate Tensile Stress } \\
(\mathbf{M P a})\end{array}$ \\
\hline Ambient & 486 & 640 \\
\hline 300 & 484 & 630 \\
\hline 500 & 462 & 602 \\
\hline 700 & 379 & 461 \\
\hline
\end{tabular}

TABLE IV. FIRE EFFECT ON THE PROPERTIES OF PRESTRESSING STRAND

\begin{tabular}{|c|c|c|c|c|c|}
\hline $\begin{array}{c}\text { Temperature } \\
\left({ }^{\circ} \mathbf{C}\right)\end{array}$ & $\begin{array}{c}\text { Yield } \\
\text { tensile } \\
\text { stress } \\
(\mathbf{M P a})\end{array}$ & $\begin{array}{c}\text { Ultimate } \\
\text { tensile } \\
\text { stress } \\
(\mathbf{M P a})\end{array}$ & $\begin{array}{c}\mathbf{7 0 \%} \\
\text { of } \\
\text { yield } \\
\text { stress } \\
(\mathbf{M P a})\end{array}$ & $\begin{array}{c}\text { Stress } \\
\text { after } \\
\text { losses } \\
(\mathbf{M P a})\end{array}$ & $\begin{array}{c}\text { Prestress } \\
\text { force } \\
\text { after } \\
\text { losses } \\
(\mathbf{k N})\end{array}$ \\
\hline ambient & 1720 & 1860 & 1204 & $1204^{*}$ & 119 \\
\hline 300 & 1700 & 1850 & 1190 & 1011.5 & 100 \\
\hline 500 & 1359 & 1414 & 951.3 & 808.6 & 80 \\
\hline 700 & 722 & 800 & 505.4 & 429.6 & 42.5 \\
\hline
\end{tabular}

$*$ the beam was tested directly after applying transfer force.

$* *$ Losses after burning $=15 \%[7]$

\section{MATERIAL BEHAVIOR IN ABAQUS}

The 3-D generalized Hooke's law is the favorite for isotropic linear elastic materials in 3-D stress conditions. Hooke's law is used to estimate the elastic strains associated with applied stresses within beams which have isotropic materials which mean that the coefficients of elastic moduli, such as Young's modulus $E$ and Poisson's ratio $v$ are included in calculations.

\section{FINITE ELEMENT EQUATIONS}

The state of stresses is represented by a very small cube with three stress components on each of its six sides (one normal and two shear components). The strain is known as the change of displacement per unit length and the components of strain can be explained by driving of the displacements to the original length as illustrated by [14]:

$$
\begin{gathered}
\varepsilon x=\frac{\partial(u)}{\partial(x)} \quad \varepsilon y=\frac{\partial(v)}{\partial(y)} \quad \varepsilon z=\frac{\partial(w)}{\partial(z)} \\
\varepsilon(x y)=\frac{\partial(u)}{\partial(y)}+\frac{\partial(v)}{\partial(x)} \\
\varepsilon(x z)=\frac{\partial(u)}{\partial(z)}+\frac{\partial(w)}{\partial(x)} \\
\varepsilon(y z)=\frac{\partial(v)}{\partial(z)}+\frac{\partial(w)}{\partial(y)}
\end{gathered}
$$

where $u, v$ and $w$ are the components of displacement in $x, y$, and $z$ direction respectively. Equations (2) showing the six strain-displacement relationships can be written in matrix form:

$$
\varepsilon=(L) .(U)
$$

where $U$ is the displacement vector and having been produced from:

$$
(U)=\left\{\begin{array}{l}
(u) \\
(v) \\
(w)
\end{array}\right\}
$$

and $L$ is a matrix of partial differential:

$$
(L)=\left[\begin{array}{ccc}
(\partial / \partial x) & 0 & 0 \\
0 & (\partial / \partial y) & 0 \\
0 & 0 & (\partial / \partial z) \\
0 & (\partial / \partial z) & (\partial / \partial y) \\
(\partial / \partial z) & 0 & (\partial / \partial x) \\
(\partial / \partial y) & (\partial / \partial x) & 0
\end{array}\right]
$$

\section{NUMERICAL ANALYSIS}

All numerical calculations were made in ABAQUS (ver. 6.13/2016). The 3D-models were configured for the dimensions of the segmental posttensioned concrete (SPC) beams. In ABAQUS, a mesh of model type C3D8R and 8-node linear hexahedral element was used as shown in Figure 4.

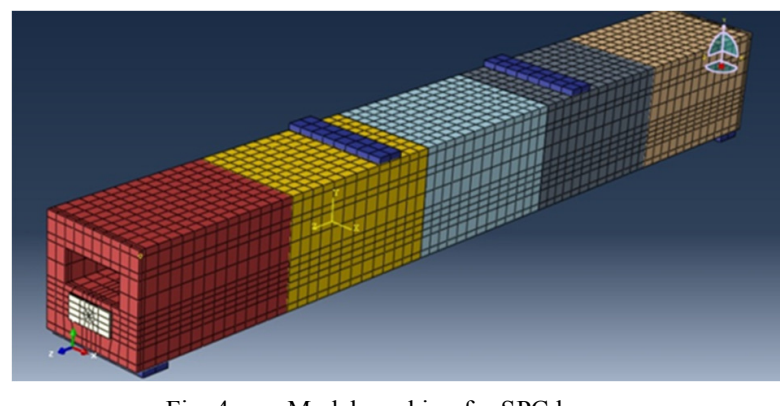

Fig. 4. Model meshing for SPC beams

The interaction module allows setting up interactions between parts. In ABAQUS, several contact interaction models exist. Each contact interaction can refer to a contact property that provides a model for interaction between the contact surfaces. Reinforced steel (main reinforcement and stirrups) elements were connected to the concrete beam elements by embedded constraints as shown in Figure 5. The reinforced steel is designed as an embedded element and the concrete beam is used as the host element. The steel bearing plate 
element is connected to the concrete beam element by using tie constraints (Figure 6). The end bearing plate element is designed as a master surface and the concrete beam is used as the slave element. The steel support plate element is connected to the concrete beam element by using tie constraints (Figure 7). The support plate element is designed as the master surface and the concrete beam is used as the slave element.

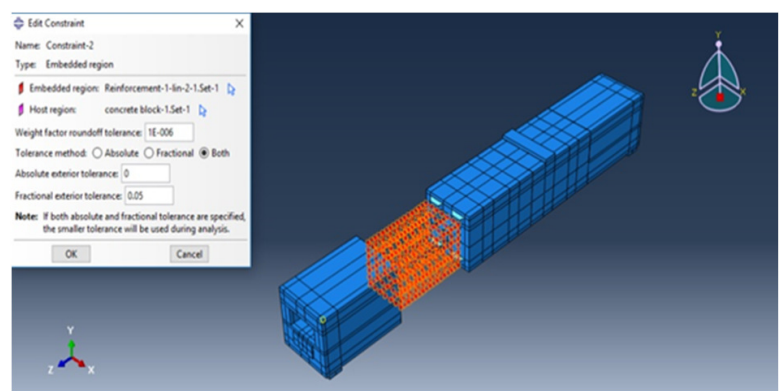

Fig. 5. Contact interaction (embedded constraint method) for steel reinforcement

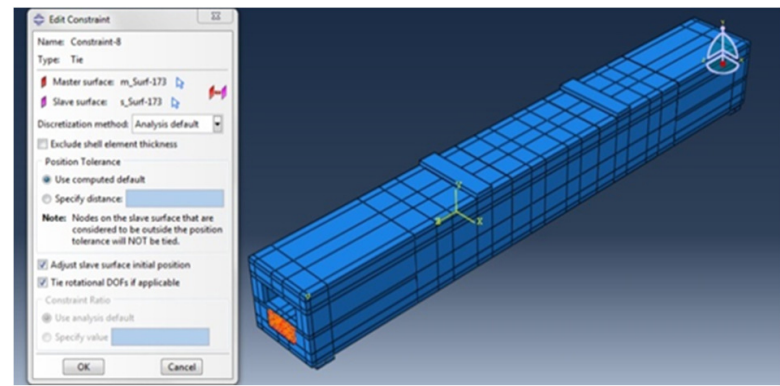

Fig. 6. Contact interaction (tie constraint method) for end bearing plate and concrete SPC beam

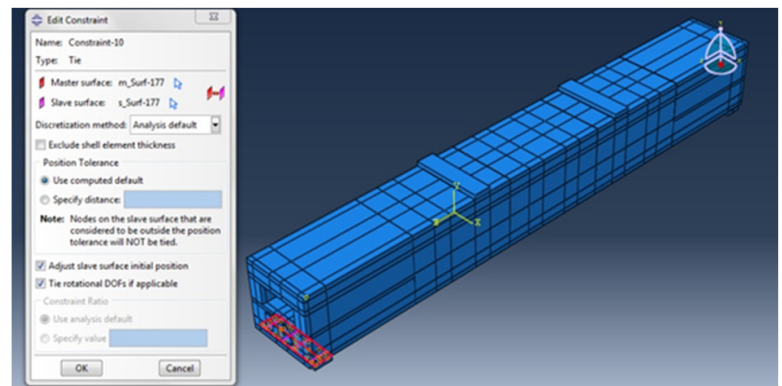

Fig. 7. Contact interaction (tie constraint method) for support plate and concrete SPC beam

The steel load plate surface was connected to the deck slab top surface by using tie constraint (Figure 8). The load plate surface is designed as the master surface and the deck slab top surface is used as the slave element. The prestressing strand element is connected to the bearing plate element by using tie constraints (Figure 9). The prestressing strand element is designed as the master surface and the bearing plate element is used as the slave element. Contact pairs were adopted for contact between the prestressing strand elements and the concrete elements (Figure 10). The prestressing strand element is designed as the master surface and the concrete beam is used as the slave element for the first contact. In addition, contact pairs were adopted for contact between two concrete element SPCs (Figure 11).

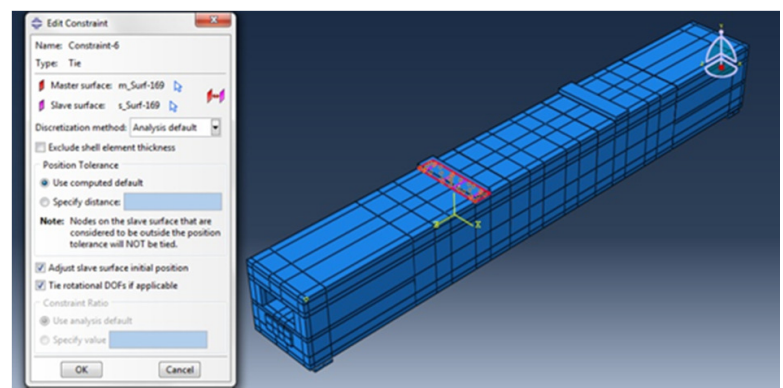

Fig. 8. Contact interaction (tie constraint method) for load plate and concrete SPC beam

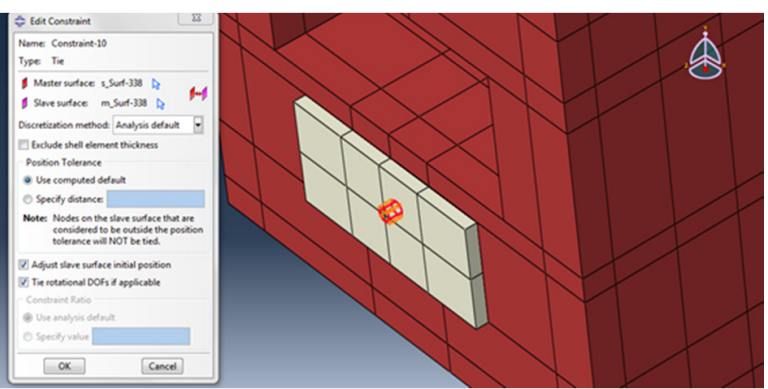

Fig. 9. Contact interaction (tie constraint method) for end bearing plate and prestressing strand

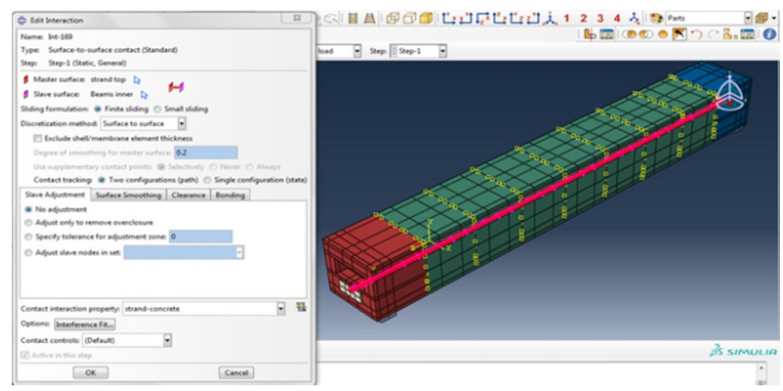

Fig. 10. Contact interaction (surface to surface method) for prestressing strand with concrete beam

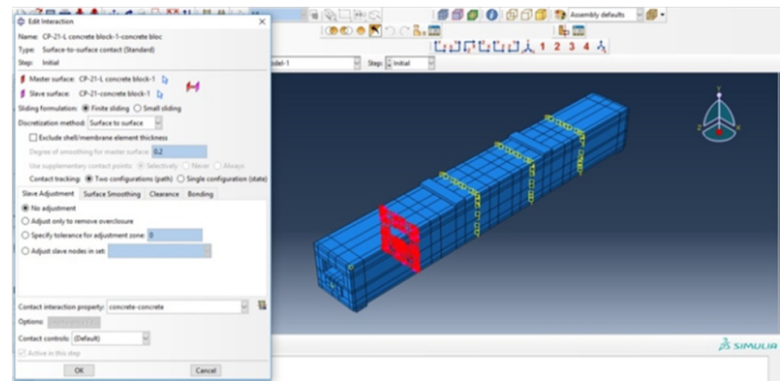

Fig. 11. Contact interaction (surface to surface method) among SPC beam segments

\section{STEPS, APPLIED LOADS AND BOUNDARY CONDITIONS}

ABAQUS allows selecting the kind of analysis that is required to be performed to the model with specifying step 
increment (automatic or fixed step increment). Each analysis step in ABAQUS is divided into several increments. The type of analysis used depends on the loading conditions and the responses which will be detected. The presented model, general static analysis type, and automatic step increment are utilized. The load cases are groups of loads and boundary conditions used to determine a particular load state. The used boundary conditions are demonstrated in Figure 12. Simply supported boundary conditions were assigned to the beam-ends. One support provided restraint to both vertical and longitudinal displacements (directions $y$ and $z$ ) while allowing rotations about the $x$ axis, (pin support). The second support provided restraints to only vertical displacements ( $y$ direction), while allowing longitudinal displacements and rotations about the $x$ plane axis, (roller support). Stress in $z$ direction as initial condition in prestressing strand equivalent to the imposed prestressing force was applied for beams subjected to external prestressing as shown in Figure 13. In the second step of modeling, the addition of pressure load was applied uniformly to each steel load plate, each plate had equal to $1 / 2$ of the actual applied pressure $P$ which was distributed over the plate area (400mm in length and $100 \mathrm{~mm}$ in width). Figure 15 illustrates the steel load plates and the applied pressure.

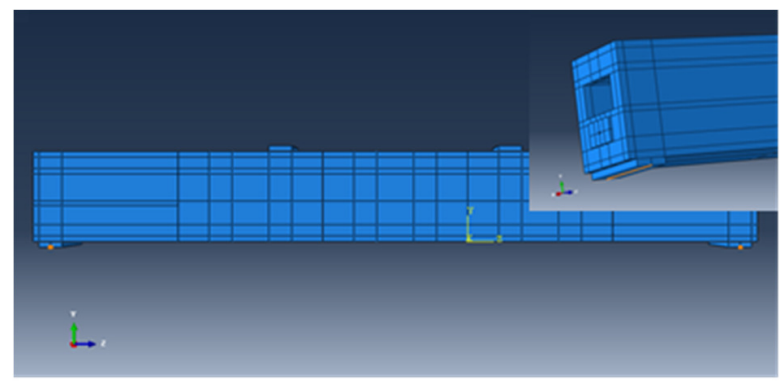

Fig. 12. Modeling of simply supported boundary condition

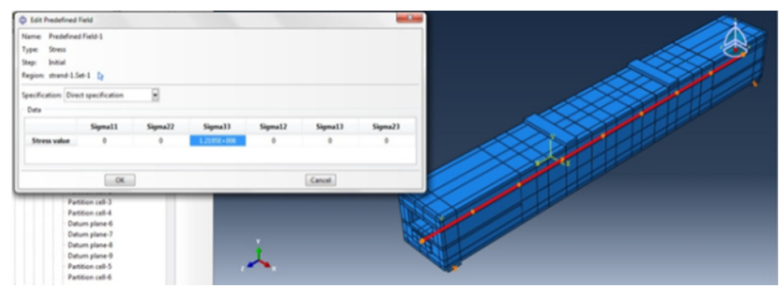

Fig. 13. Modeling of prestressing force

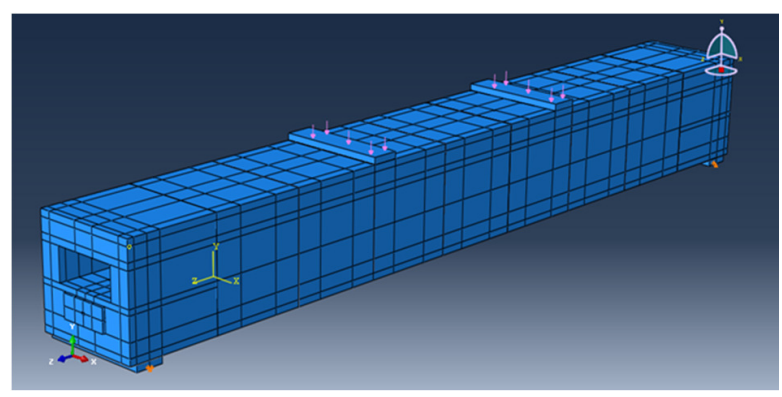

Fig. 14. Applied load

\section{MODELING OF SPC BEAM AFTER BURNING}

All previous modeling steps for the unburned SPC beam (reference specimen) were repeated to create and analyze post-fire SPC beams but with the use of material mechanical properties for model components after burning at $300^{\circ} \mathrm{C}$ and cooling to study the behavior of load-deflection relations, load-strain relations, failure mode and load carrying capacity, and compare the results with the behavior of the reference model. These processes were repeated to model the burned SPC beams at $500^{\circ} \mathrm{C}$ and $700^{\circ} \mathrm{C}$. Some facilities available in the ABAQUS software were used to model the composite prestressed concrete beam after burning by making a copy of the unburned specimen to represent the SPC beam model (after burning) at burning temperature of 300,500 , and $700^{\circ} \mathrm{C}$ as shown in Figure 15. The material properties changed by using material mechanical properties for model components and are listed in Tables II-IV.

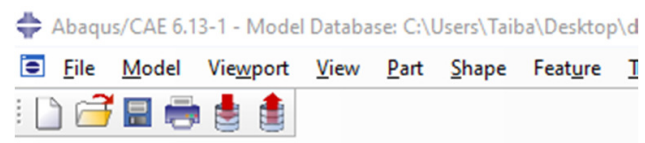

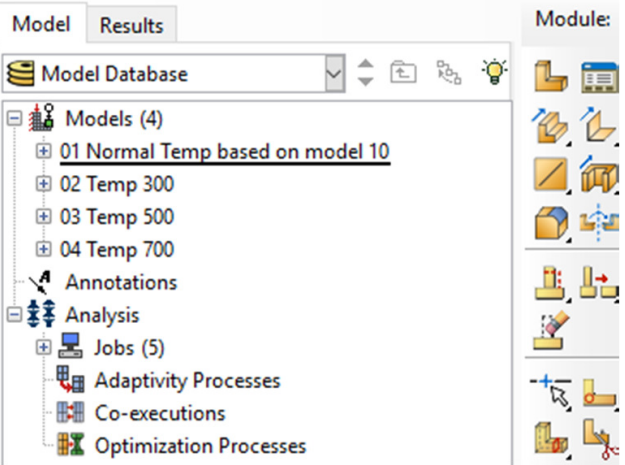

Fig. 15. Modelling of SPC beams (after burning)

\section{CALIBRATION OF THE FABRICATED FE MODELS}

In this section, several comparisons are made with the experimental results. These include pre-stress effect, loaddeflection relation under the applied load, and load at failure stage of the reference and post-fire SPC beams.

\section{A. Effect of Prestressing Force}

The upward deflection (camber), obtained from the experimental work and the FE analysis because of the pre-stress effect, caused by applying eccentric prestressing force for the FE model of SPC composes of different segments number, is shown in Table V.

TABLE V. PRE-STRESS EFFECT

\begin{tabular}{|c|c|c|c|c|}
\hline Group & $\begin{array}{c}\text { Segments } \\
\text { number }\end{array}$ & $\begin{array}{c}\text { Experimental } \\
\text { camber }(\mathbf{m ~ m})\end{array}$ & $\begin{array}{c}\text { FEM camber } \\
\mathbf{( m m})\end{array}$ & FEM/EXP. \\
\hline Group I & 9 & 2.9 & 3.02 & 1.04 \\
\hline Group II & 7 & 2.3 & 2.51 & 1.09 \\
\hline Group III & 5 & 1.8 & 1.94 & 1.08 \\
\hline
\end{tabular}




\section{B. Load-Deflection Relation}

The results from the FE analysis for the load versus deflection relation for static analysis models are presented in Figures 16 to 27, showing the comparisons between the experimental and numerical results. It can be observed that, the numerical models were stiffer than the experimental data in both linear and nonlinear regions of the behavior, but there was a good agreement between them. In the brackets, the number of segments and the burning temperature are referred ( $\mathrm{R}$ is for the Reference sample)

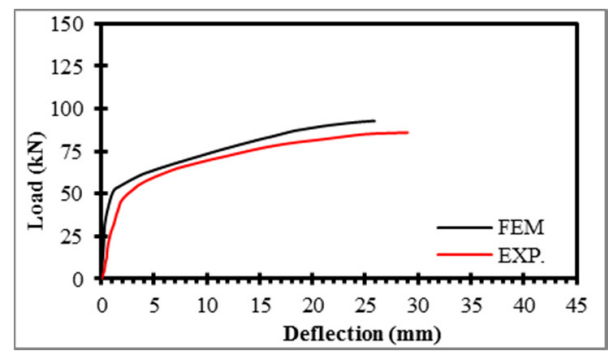

Fig. 16. Comparison of load-deflection relation of SPC beam [9-R]

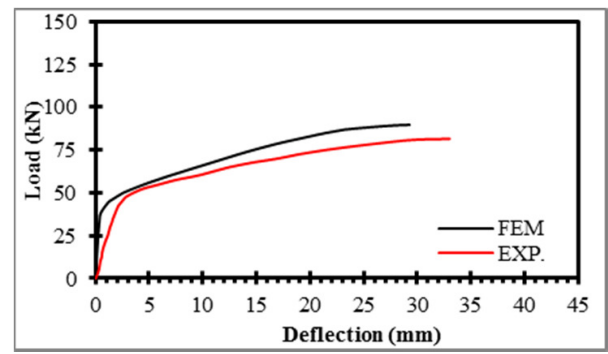

Fig. 17. Comparison of load-deflection relation of SPC beam $\left[9-300^{\circ} \mathrm{C}\right]$

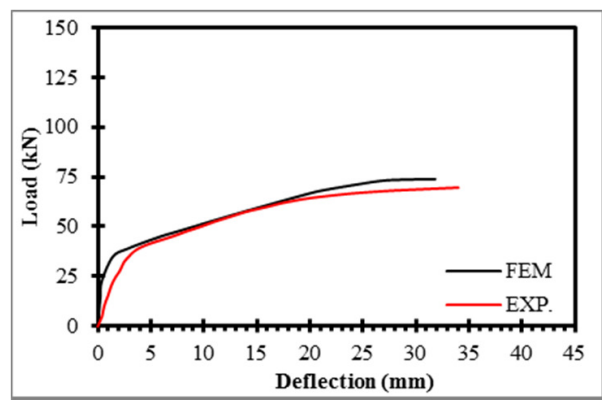

Fig. 18. Comparison of load-deflection relation of SPC beam $\left[9-500^{\circ} \mathrm{C}\right]$

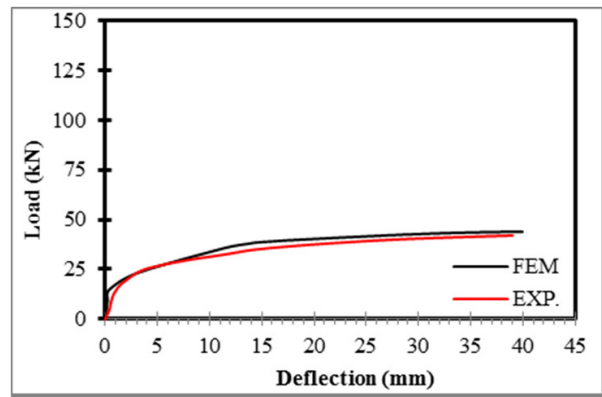

Fig. 19. Comparison of load-deflection relation of SPC beam $\left[9-700^{\circ} \mathrm{C}\right]$

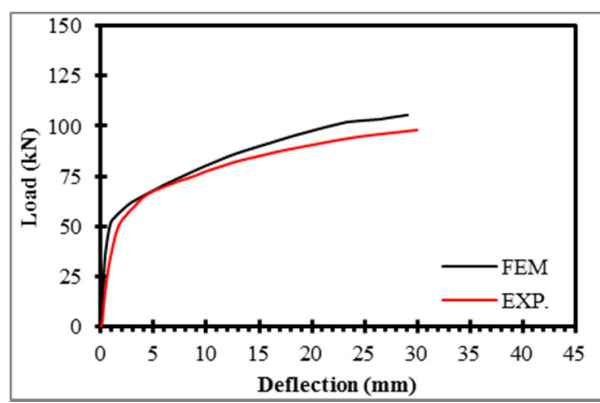

Fig. 20. Comparison of load-deflection relation of SPC beam [7-R]

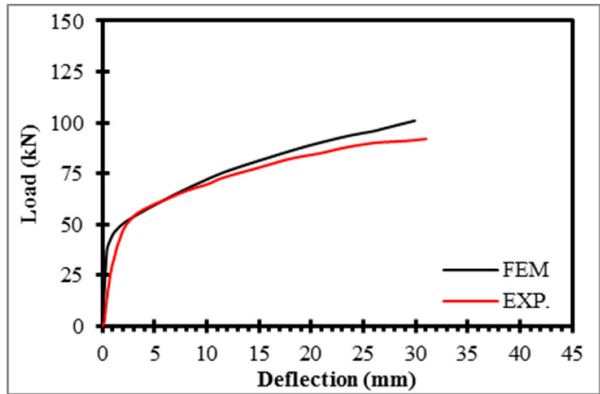

Fig. 21. Comparison of load-deflection relation of SPC beam $\left[7-300^{\circ} \mathrm{C}\right]$

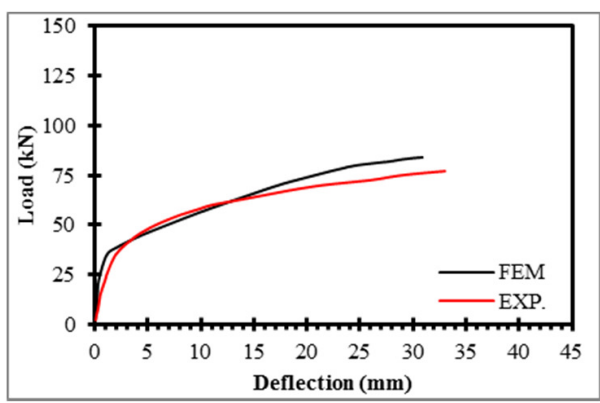

Fig. 22. Comparison of load-deflection relation of SPC beam $\left[7-500^{\circ} \mathrm{C}\right]$.

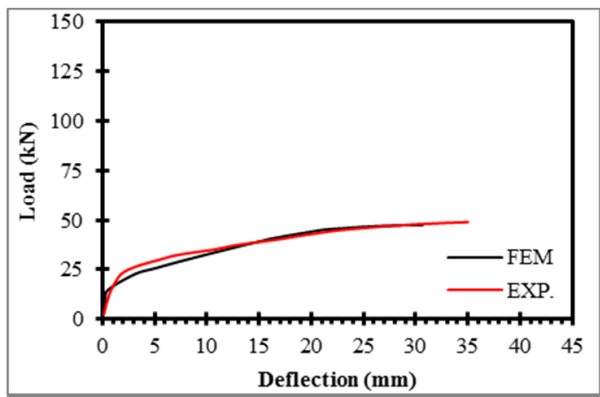

Fig. 23. Comparison of load-deflection relation of SPC beam $\left[5-700^{\circ} \mathrm{C}\right]$

\section{Load at Failure}

Table VI shows the load of failure values found in FE analysis and experimental work for all specimens under static test. All failure loads obtained from FE analysis show an overestimation comparing to the real experimental values.

\section{Numerical CASE STUDY}

The main goal of this research is to find the effect of the segment number on the post-fire behavior of the segmental 
prestressed concrete beams whose results were too complicated to be obtained by experimental work.

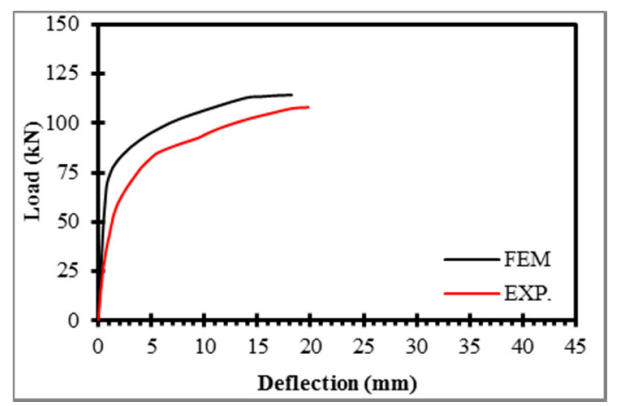

Fig. 24. Comparison of load-deflection relation of SPC beam [5-R]

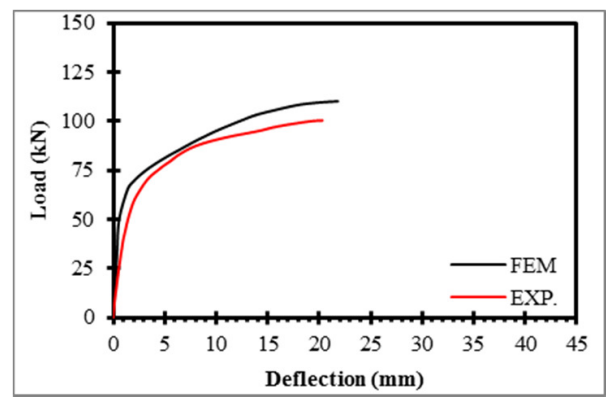

Fig. 25. Comparison of load-deflection relation of SPC beam $\left[5-300^{\circ} \mathrm{C}\right]$

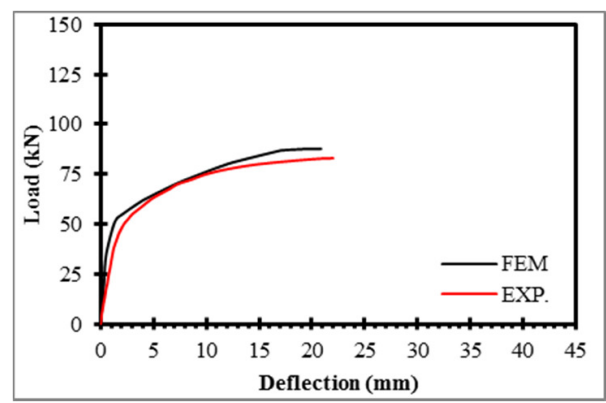

Fig. 26. Comparison of load-deflection relation of SPC beam $\left[5-500^{\circ} \mathrm{C}\right]$

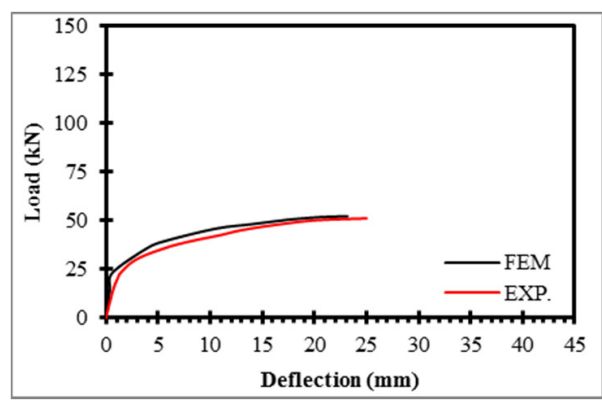

Fig. 27. Comparison of load-deflection relation of SPC beam $\left[5-700^{\circ} \mathrm{C}\right]$

The case study was represented by using ABAQUS finite element modeling software. In the case study, reported information regarding the beam design and temperature of the particular fire of 300,500 and $700^{\circ} \mathrm{C}$ has been applied to the SPC beams as shown in Tables I-IV. In this section, the results from the FEM are showed for the 12 SPC beams that were mentioned in Table I and comparisons are made with the obtained results, including strand strains of the reference and post-fire SPC beams and concrete strains of the reference SPC beams.

TABLE VI. FAILURE LOAD COMPARISON

\begin{tabular}{|c|c|c|c|c|}
\hline & \multirow{2}{*}{ Specimen } & \multicolumn{2}{|c|}{ Failure Load (kN) } & \multirow{2}{*}{$(P u) \mathrm{FE} /(P u) \operatorname{Exp}$} \\
\hline & & $(P u) F E$ & $(P u)$ Exp. & \\
\hline \multirow{4}{*}{ Group I } & SPC- $9-25 \mathrm{C}^{\circ}$ & 93 & 86 & 1.08 \\
\hline & SPC-9-300C ${ }^{\circ}$ & 90 & 82 & 1.1 \\
\hline & SPC-9-500C ${ }^{\circ}$ & 74 & 70 & 1.06 \\
\hline & SPC-9-700C ${ }^{\circ}$ & 44 & 42 & 1.05 \\
\hline \multirow{4}{*}{ Group II } & SPC-7-25C ${ }^{\circ}$ & 105 & 98 & 1.07 \\
\hline & SPC-7-300C ${ }^{\circ}$ & 101 & 92 & 1.1 \\
\hline & SPC-7-500C ${ }^{\circ}$ & 84 & 77 & 1.09 \\
\hline & SPC-7-700C ${ }^{\circ}$ & 48 & 49 & 0.98 \\
\hline \multirow{4}{*}{ Group III } & SPC $-5-25 \mathrm{C}^{\circ}$ & 114 & 108 & 1.06 \\
\hline & SPC $-5-300 \mathrm{C}^{\circ}$ & 110 & 101 & 1.09 \\
\hline & SPC $-5-500 \mathrm{C}^{\circ}$ & 88 & 83 & 1.06 \\
\hline & SPC $-5-700 \mathrm{C}^{\circ}$ & 52 & 51 & 1.02 \\
\hline
\end{tabular}

\section{A. Strand Strains}

This section discusses the variation of the strand's strain with the variation of the applied load for all the SPC beams. Firstly, the relationship was linear, and with more increase in the applied load the response became nonlinear. Figures 28-30 show the load versus strains for the strand of SPC beams of groups I-III that were exposed to different temperatures. The Figures exhibit that, increasing burning temperature led to decrease in SPC beam strand strains. Also, the initial strain conserved approximately about one-third of the ultimate SPC beams capacity. After that, descending was observed, with different rates, depending on the residual material properties. In all the tested SPC beams the ultimate strand strain was not reached, i.e. strand rupture was not detected. The nonlinearity stage of the curves could be caused by the increase in strand stress as beam curvature increased due to high deflection and its joints opening distance at the tension lower chord of the SPC beams. Figures 31-34 show the comparison between SPC beam's behavior composed of different segment numbers but with the same exposure conditions. It can be noticed that the difference is not considerable. Table VII shows the limit of the strain reached in strand for all SPC beams at ultimate load.

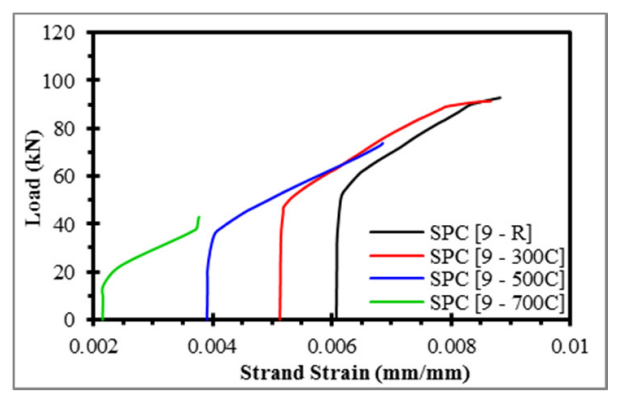

Fig. 28. Load-strand strain curves of Group I, FEM analysis

\section{B. Concrete Strains in the SPC Beams}

The tension strains in the segmental concrete beams have a negligible value due to the regular cracks that occurred in the beams formed from the joints between. 


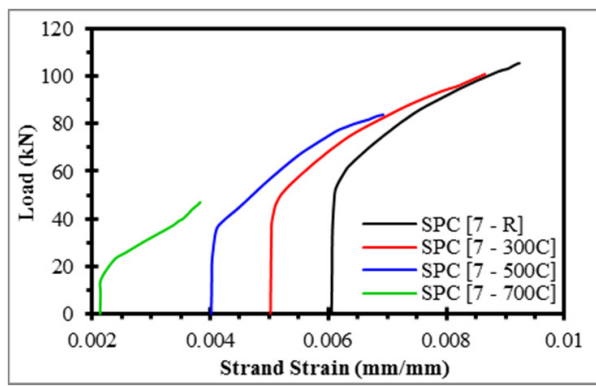

Fig. 29. Load-strand strain curves of Group II, FEM analysis

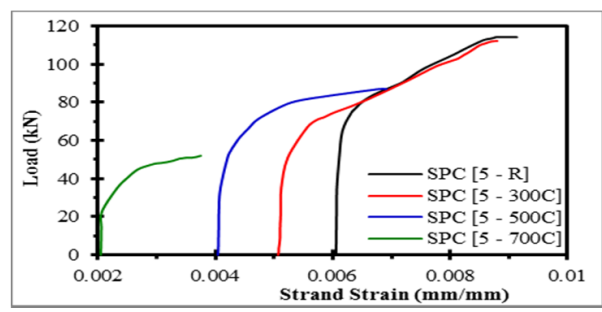

Fig. 30. Load-strand strain curves of Group III, FEM analysis

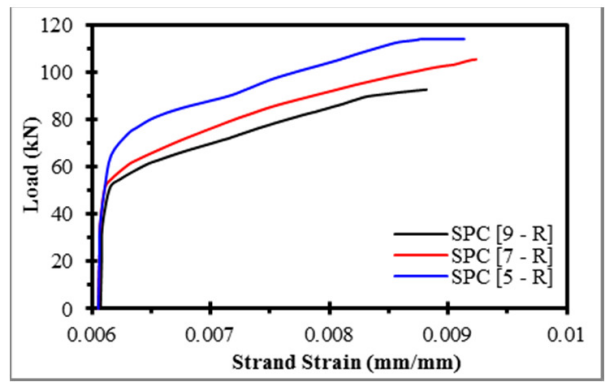

Fig. 31. Load-strand strain curves for unburned SPC beams, FEM analysis

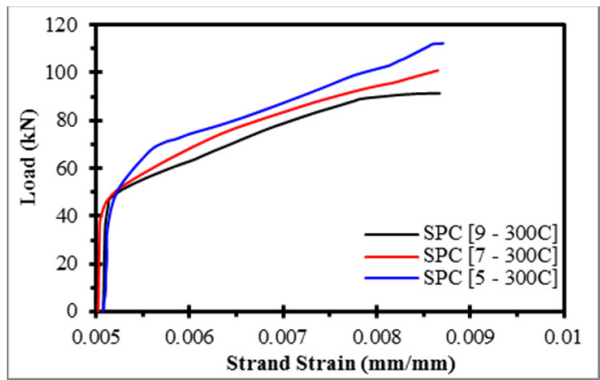

Fig. 32. Load-strand strain curves for SPC beams at $300^{\circ} \mathrm{C}, \mathrm{FEM}$ analysis

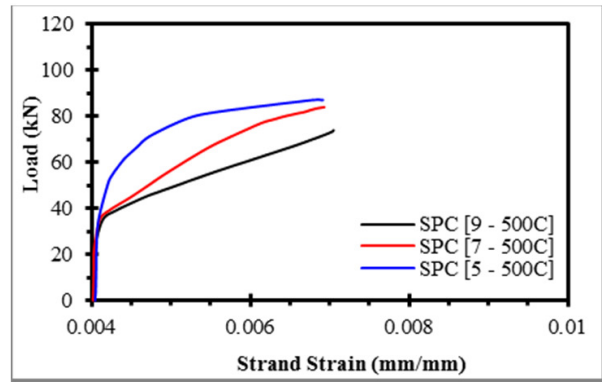

Fig. 33. Load-strand strain curves for SPC beams at $500^{\circ} \mathrm{C}, \mathrm{FEM}$ analysis

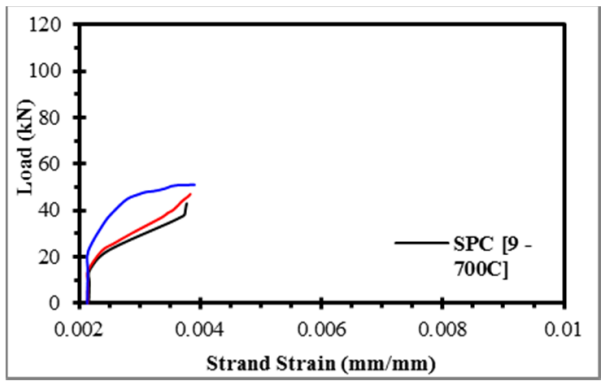

Fig. 34. Load-strand strain curves for SPC beams at $700^{\circ} \mathrm{C}$, FEM analysis

TABLE VII. STRAND STRAIN VALUES FOR THE TESTED SPC BEAMS

\begin{tabular}{|c|c|c|c|c|}
\hline \multicolumn{2}{|c|}{ Group No. } & $\begin{array}{l}\text { Initial Strain } \\
\text { (microstrain) }\end{array}$ & $\begin{array}{c}\text { Final total strain } \\
\text { (microstrain) }\end{array}$ & $\begin{array}{l}\text { Burned/ unburned } \\
\text { ultimate strain \% }\end{array}$ \\
\hline \multirow{4}{*}{ כ) } & SPC-9-R & 6074 & 8819 & 100 \\
\hline & SPC-9-300C ${ }^{\circ}$ & 5078 & 8673 & 98 \\
\hline & SPC-9-500C $^{\circ}$ & 4020 & 7048 & 80 \\
\hline & SPC-9-700C ${ }^{\circ}$ & 2156 & 3775 & 43 \\
\hline \multirow{4}{*}{ 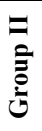 } & SPC-7-R & 6056 & 9236 & 100 \\
\hline & SPC-7-300C & 5021 & 8654 & 94 \\
\hline & SPC-7-500C & 4017 & 6930 & 75 \\
\hline & SPC-7-700C & 2135 & 3830 & 42 \\
\hline \multirow{4}{*}{ 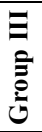 } & SPC-5-R & 6052 & 9129 & 100 \\
\hline & SPC $-5-300 \mathrm{C}^{\circ}$ & 5064 & 8794 & 96 \\
\hline & SPC-5-500C & 4042 & 6913 & 76 \\
\hline & $\mathrm{SPC}^{-5-700 \mathrm{C}^{\circ}}$ & 2130 & 3869 & 42 \\
\hline
\end{tabular}

The numerical results from ABAQUS proved that the tensile strain at the bottom surface of the beams had a small value approaching the limit of 35 microstrain. The tensile strain distribution of the bottom chord at the middle segment for the reference SPC beams (SPC 9-R), (SPC 7-R) and (SPC 5-R) are shown in Figures 35-37.

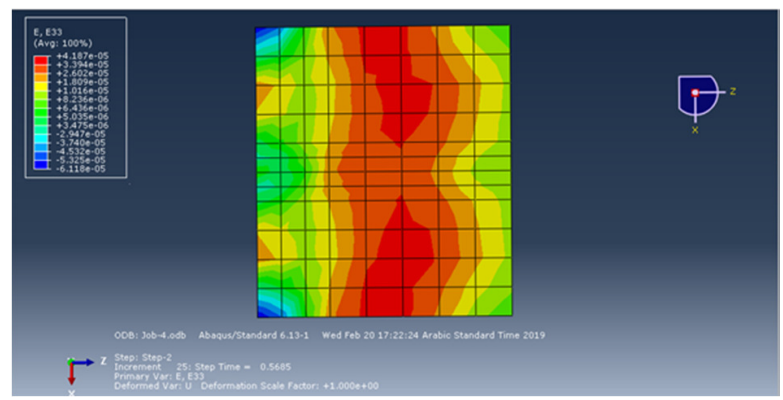

Fig. 35. Strain profile at lower surface of SPC [9-R] middle segment

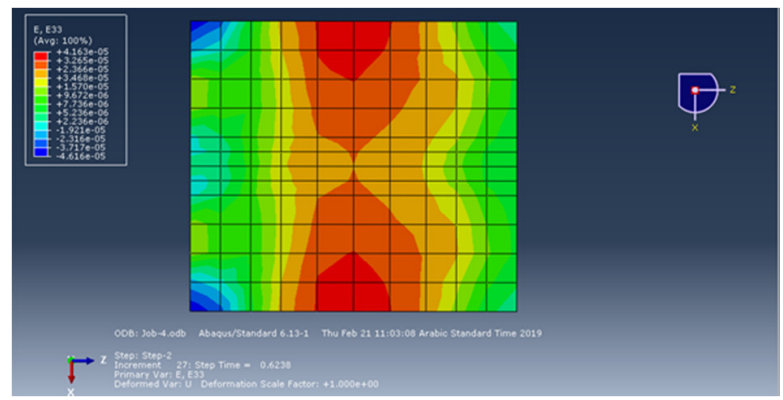

Fig. 36. Strain profile at lower surface of SPC [7-R] middle segment 


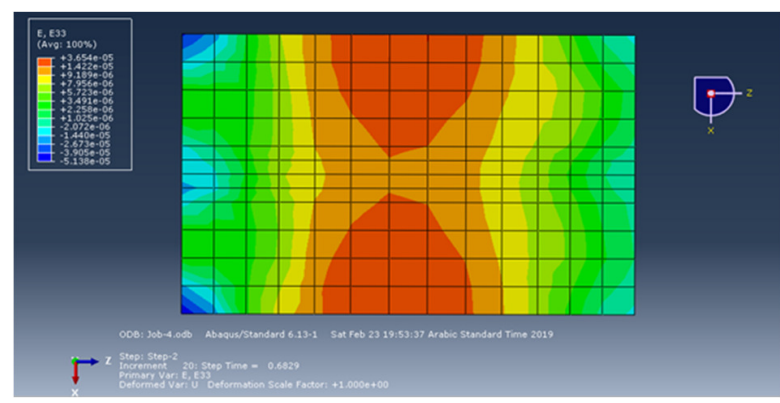

Fig. 37. Strain profile at lower surface of SPC [5-R] middle segment

The compression strains in the middle segment of the segmental concrete beams reached maximum compressive strain near the region of joint between adjacent segments. The numerical results proved that the compressive strains at the top surface of the beams had maximum concrete strain value approaching to the limit of 3000 microstrain. The compressive strain distribution of the top chord at the middle segment for the reference SPC beams (SPC 9-R), (SPC 7-R), and (SPC 5$\mathrm{R}$ ) are shown in Figures 38, 39, and 40 respectively.

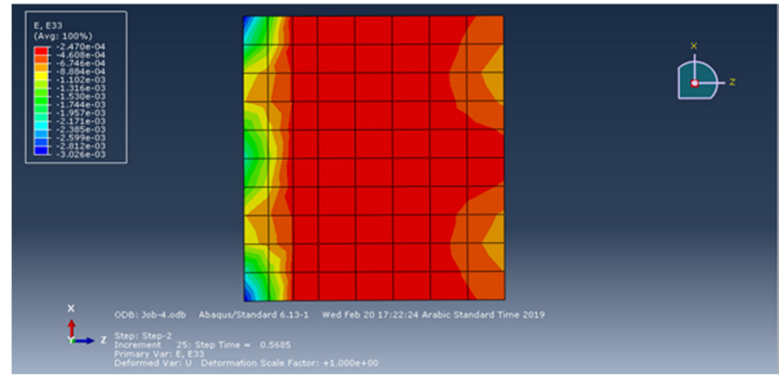

Fig. 38. Strain profile at upper surface of SPC [9-R] middle segment

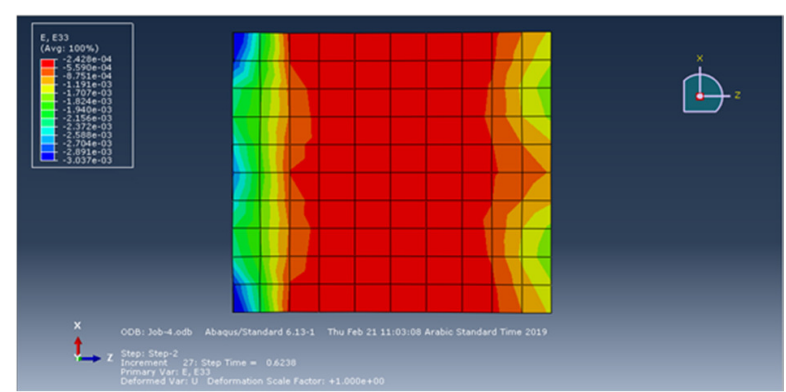

Fig. 39. Strain profile at upper surface of SPC [7-R] middle segment

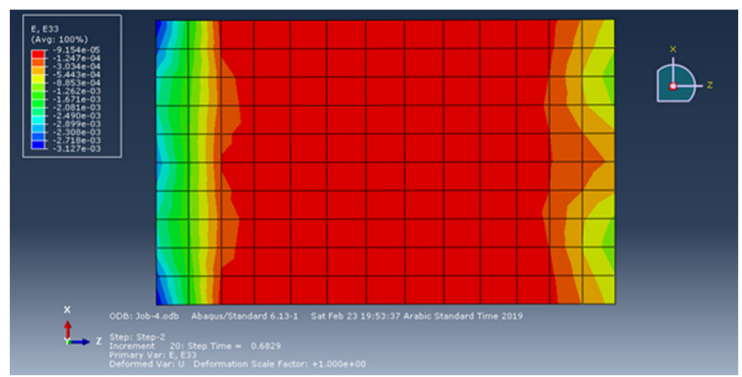

Fig. 40. Strain profile at upper surface of SPC [5-R] middle segment
All SPC beams failed in crushing of concrete in the compression zone. This crushing occurred between the central and it two adjacent segments. The numerical results proved that failure of control SPC beams occurred by crushing the concrete at the central segment and its left adjacent segment. The failure mode at the plastic strain stage in ABAQUS analysis for the references SPC beams (SPC 9-R), (SPC 7-R) and (SPC 5-R) are shown in Figures 41, 42, and 43, respectively.

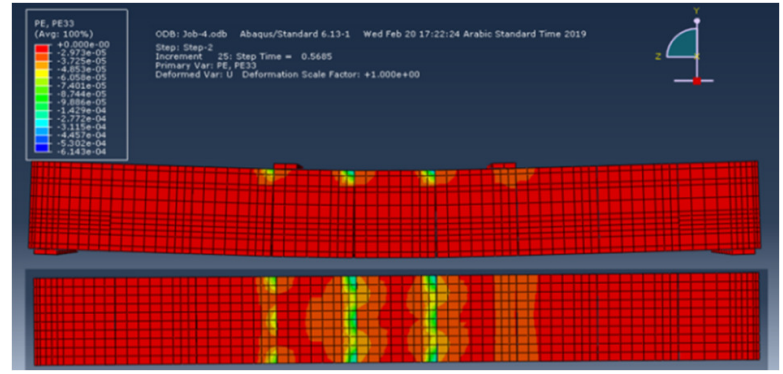

Fig. 41. Failure mode for the reference SPC beam composed of 9 segments

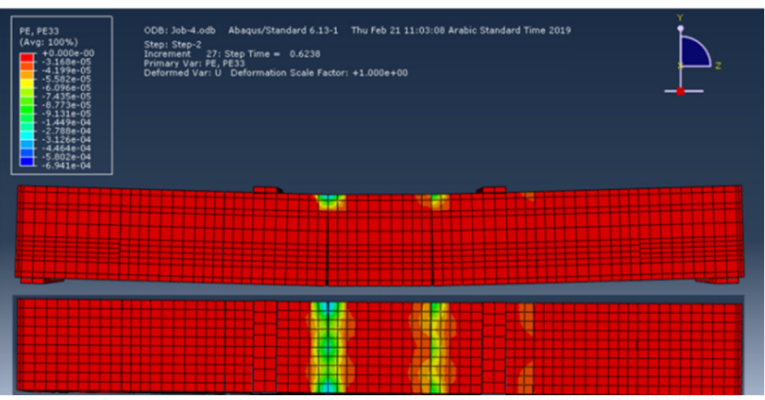

Fig. 42. Failure mode for the reference SPC beam composed of 7 segments

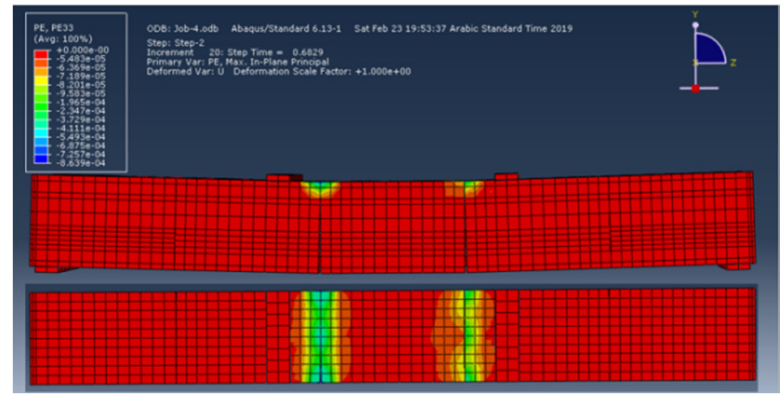

Fig. 43. Failure mode for the reference SPC beam composed of 5 segments

\section{DISCUSSION}

From the FE analysis result (load-deflection relation under the applied load), it can be seen that the models are stiffer than the experimental specimens. There are some influences that may cause higher stiffness in FEM analysis. Microcracks resulting from the drying shrinkage and curing were found in concrete during the experiments and after burning and cooling. These would decrease the actual specimens' stiffness. Modeling of these microcracks is not found in finite element models. The bond between concrete and reinforcing steel in the finite element analysis is assumed to be perfect. This assumption is not always true for the real specimens. When a 
bond slip happens, composite work is lost between concrete and reinforcing steel.

\section{CONCLUSIONS}

- The finite element models using ABAQUS show a good prediction to the behavior of the segmental prestressed concrete beams composed of different segment numbers.

- Test results showed that with increasing burning temperature the SPC beam load carrying capacity decreases, which means that beam stiffness decreases.

- With decreasing segment number of the SPC beams the load carrying capacity increased for the same burning temperature.

- The comparison of burned to unburned strain at the end of loading test was $98 \%, 80 \%$ and $43 \%, 94 \%, 75 \%$ and $42 \%$, and $96 \%, 76 \%$ and $42 \%$ for SPC beams of Groups I, II, and III at burning temperatures of $300^{\circ} \mathrm{C}, 500^{\circ} \mathrm{C}$ and $700^{\circ} \mathrm{C}$, respectively.

- The unburned SPC beams of 7 and 5 segments reveal increase in strain ratio by $105 \%$ and $104 \%$ respectively compared to that of SPC beams of 9 segments. For the SPC beams burned at $300^{\circ} \mathrm{C}, 500^{\circ} \mathrm{C}$ and $700^{\circ} \mathrm{C}$, this ratio was $99 \%, 101 \%, 98 \%, 98 \%$, and $101 \%, 102 \%$ for beams made up of 7 and 5 segments compared to that of 9 segments.

\section{REFERENCES}

[1] M. A. Algorafi, A. A. A. Ali, I. Othman, M. S. Jaafar, M. P. Anwar, "Experimental study of externally prestressed segmental beam under torsion", Engineering Structures, Vol. 32, No. 11, pp. 3528-3538, 2010

[2] C. Sivaleepunth, J. Niwa, D. H. Nguyen, T. Hasegawa, Y. Hamada, "Shear carrying capacity of segmental prestressed concrete beams", Doboku Gakkai Ronbunshuu E, Vol. 65, No. 1, pp. 63-75, 2009

[3] D. H. Nguyen, K. Watanabe, J. Niwa, T. Hasegawa, "Modified model for shear caryying capacity of segmental concrete beams with external tendons", Doboku Gakkai Ronbunshuu E, Vol. 66, No. 1, pp. 53-67, 2010

[4] M. A. Al-Gorafi, A. A. A. Ali, I. Othman, M. S. Jaafar, M. P. Anwar, "Externally prestressed monolithic and segmental concrete beams under torsion: a comparative finite element study", IOP Conference Series: Materials Science and Engineering, Vol. 17, Article ID 012041, IOP Publishing, 2011

[5] Y. N. Chan, X. Luo, W. Sun, "Compressive strength and pore structure of high-performance concrete after exposure to high temperature up to $800^{\circ}$ C", Cement and Concrete Research, Vol. 30, No. 2, pp. 247-251, 2000

[6] C. S. Poon, S. Azhar, M. Anson, Y. L. Wong, "Comparison of the strength and durability performance of normal- and high-strength pozzolanic concretes at elevated temperatures", Cement and Concrete Research, Vol. 31, No. 9, pp. 1291-1300, 2001

[7] B. Georgali, P. E. Tsakiridis, "Microstructure of fire-damaged concrete. A case study", Cement and Concrete Composites, Vol. 27, No. 2, pp. 255-259, 2005

[8] F. Aslani, "Prestressed concrete thermal behaviour", Magazine of Concrete Research, Vol. 65, No. 3, pp. 158-171, 2013

[9] L. Zhang, Y. Wei, F. Au, "Mechanical properties of prestressing steel at elevated temperature and after cooling", Australasian Conference on the Mechanics of Structures and Materials, Southern Cross University, Australia, December 9-12, 2014

[10] A. H. Buller, M. Oad, B. A. Memon, S. Sohu, "24-hour Fire Produced Effect on Reinforced Recycled Aggregates Concrete Beams",
Engineering Technology and Applied Science Research, Vol. 9, No. 3, pp. 4213-4217, 2018

[11] U. Wickstorm, A Very Simple Method for Estimating Temperature in Fire Exposed Concrete Structures, Technical Report SP-RAPP 1986:45, Swedish National Testing Institute, 1986

[12] Z. Wang, K. Tan, "Residual area method for heat transfer analysis of concrete-encased I-sections in fire", Engineering Structures, Vol. 28, pp. 411-422, 2006

[13] E. Ellobody, C. Bailey, "Modelling of unbonded post-tension concrete slabs under fire conditions", Fire Safety Journal, Vol. 44, pp. 159-167, 2009

[14] G. Liu, S. Quek, The Finite Element Method: A Practical Course, Butterworth-Heinemann, 2003 